\title{
Czech Agrarian Foreign Trade According to the Degree of Processing
}

\author{
Karina Pohlová ${ }^{1}$, Luboš Smutka², Adriana Laputková ${ }^{3}$, Miroslav Svatoš ${ }^{2}$ \\ ${ }^{1}$ Institute of Agricultural Economics and Information, Prague, Czech Republic \\ ${ }^{2}$ Department of Economics, Faculty of Economics and Management, Czech University of Life Sciences \\ Prague, Czech Republic \\ ${ }^{3}$ Department of Languages, Faculty of Economics and Management, Czech University of Life Sciences \\ Prague, Czech Republic
}

\begin{abstract}
Added value of Czech agrarian trade is a frequently discussed topic. The goal of the New Strategy of the Ministry of Agriculture with the outlook until 2030 and of the Export Strategy of the Czech Republic for 2012-2020 is to improve the commodity structure of Czech agrarian exports and to increase the proportion of exported processed products and food with high added value. One of the key aspects to understanding the current state of the development of agrarian trade added value is methodology used for trade performance analysis. In fact, there are several methodologies related to attempts to estimate the real state of added value distribution in relation to foreign trade performance. None of the methods seems flawless, each is suitable for a different purpose in understanding the commodity structure specifics. Czech authorities apply methodology originally proposed by Regmi (2005) which, however, does not truly reflect the real state of the current commodity structure. The Research Institute of Agricultural Economics and Informatics is interested in developing its own method suitable for better understanding of the Czech agrarian foreign trade specifics. The objective of this paper is to specify the basic idea of the proposed methodology, to compare it with the already applied methodology and to present basic differences between the old and the new approaches. Presumably, the new classification can serve as a suitable tool for Czech agrarian trade analysis and provides a more precise overview of the degree of processing of traded commodities than other types of categorisation. Its advantages prevail over the disadvantages, which are less important. The new classification of unprocessed and processed products requires regular inspection and more frequent updates, as the 8-digit codes of the customs nomenclature continually change. At the end of the paper the agricultural trade performance is calculated according to the currently applied methodology and also according to the new proposed methodology. The results between both applied approaches are significant especially in mutual relation between processed and unprocessed items share in total trade. There are significant differences both in relation to EU countries and also non-EU countries.
\end{abstract}

\section{Keywords}

Agrarian foreign trade, degree of processing, unprocessed commodities, processed products.

Pohlová, K., Smutka, L., Laputková, A. and Svatoš, M. (2018) "Czech Agrarian Foreign Trade According to the Degree of Processing", AGRIS on-line Papers in Economics and Informatics, Vol. 10, No. 3, pp. 103-118. ISSN 1804-1930. DOI 10.7160/aol.2018.100309.

\section{Introduction}

Added value of Czech agrarian trade has recently been the focus of attention. There are many studies focused on agricultural sector value performance (e.g. Vokorokosova, 2005; Nešvera, 2006; Pulkrábek et al., 2007; Pohlová and Mezera, 2014; Burianová 2011a and 2011b; Šimáková and Stavárek, 2015; Honig et al., 2018; Pohlová et al., 2016; Rovný et al., 2010; Čermák et al., 2017; Maitah et al., 2016a; Maitah et al., 2016b; Rezbová et al., 2015). The goal of the New Strategy of the Ministry of Agriculture with the outlook until 2030 and of the Export Strategy of the Czech Republic for the period between 2012 and 2020 is to improve the commodity structure of Czech agrarian exports and to increase the proportion of exported processed products and food with high added value. To attain it, it is necessary not only to change the physical structure of agricultural trade, but also to identify the trade commodity structure accurately. Its qualified assessment is impossible without adequate classification of processed products within the agrarian products category 
(defined by HS 01-24). Examination of available materials has revealed that there is no suitable definition; furthermore, it cannot be formulated without some inaccuracy and simplification. However, a degree of simplification influences practical application (simplicity/rapidity of use and the necessity for subsequent updates when changes of customs tariffs occur, with the changes occurring more frequently in the high-digit level of the nomenclature). The types of classification currently available differ from each other, providing various viewpoints, purposes, and level of details. For example, when using the Harmonised ${ }^{1}$ or the SITC systems, international comparisons are possible. Moreover, less detailed categorization occurs most frequently in analyses and models of all economic sectors, not only of agriculture. For this reason, categories of unprocessed and processed products within various classifications overlap and sometimes diverge, and a review of the existing types of classification and creation of a new one is necessary.

The following is the available classification of processed and unprocessed agrarian products:

Regmi et al (2005) define four categories: bulk commodities, horticultural products, semiprocessed products, and processed products. The first two depend on the availability of land, geography and climatic conditions while the last two are less dependent on these factors and undergo some transformation prior to their final use and, in principle, can be produced almost anywhere (they require mainly technological know-how, labour and capital). This classification is based on 4 and 6-digit HS codes and allows international comparison; however, it is insufficiently detailed. Furthermore, live animals are defined by Regmi et al. (2005) as semi-processed products, which is questionable as they could also be considered a raw material. Moreover, one of the most important Czech export items - raw milk - included in "nonconcentrated milk and cream" (HS 0401) pertains to (high) processed products in such classification. Additionally, the classification was created for agrarian products defined by the Agreement on Agriculture by WTO, which also contains cotton, silk, furs and other commodities (several chapter headings in $\mathrm{CN} 33,35.38,41,43$ and $51-53$ ),

\footnotetext{
1 The Harmonized Commodity Description and Coding System generally referred to as "Harmonized System" or simply "HS" is a multipurpose international product nomenclature developed by the World Customs Organization (WCO, 2017). The 8-digit combined nomenclature of EU $(\mathrm{CN})$, based on 6-digit $\mathrm{HS}$, is a too for classifying goods, set up to meet the requirements both of the Common Customs Tariff and of EU's external trade statistics. $\mathrm{CN}$ is also used in intra-EU trade statistics.
}

but does not include fish, seafood and the products thereof. The IEEI currently uses slightly modified Regmi classification, which provides a base for several OECD documents (OECD, 2007; OECD, 2011; Liapis 2011).

Monthly, the European Commission publishes Monitoring on EU Agri-Food Trade. Agri-food products are specified based on the WTO definition, on 6-digit HS codes (previously 4 digit) and divided into six categories: commodities, other primary agricultural products, agricultural processed products including wine, food preparations, beverages, and non-edible products (the originallyapplied methodology divided the trade items only into three categories: bulk commodities, intermediates, customer-oriented products). Apart from unprocessed commodities, the Commodities and Other primary agricultural products also include milling products, malt, starch, meat, dairy products except for cheese, dried and frozen fruit, and other. All vegetable oils are considered commodities, but olive oil is regarded as a processed product.

Lindland (1997) uses the FAOSTAT agricultural commodity list in his study. His classification consists of three categories, namely primary commodities $(\mathrm{L}=0)$, processed commodities processed directly from a primary commodity $(\mathrm{L}=1)$, and processed commodities that are a product of two or more processing operations $(\mathrm{L}>1)$. Contrary to the FAOSTAT definition, livestock products, such as meat, fat and offal, have been considered as processed products rather than primary commodities. In the RIEE's ${ }^{2}$ project with FAO (FAO, 1994), Ratinger and Matthews (1999) created four categories of commodities: one unprocessed and three with processed products, depending on the degreeoffinalisation. Twocategories of agrarian products, raw and processed, are used in Bureau et. al's study (2014) which does not contain any complete list of codes, although it does contain some information in its annex. For example, fresh or chilled fish, dried pulses, and dried fruit (in contrast to dried vegetables) are classified as raw goods. In addition, the agri-food sector does not refer to the products mentioned in HS 01-24 only, but also to modified starches, raw furs and skins, as well raw and fuel wood. The authors use the BACI database by $\mathrm{CEPII}^{3}$ (that is UN Comtrade data) as a source. International commerce in processed foods is analysed by Henderson et al. (1996) who discuss food and related products

\footnotetext{
${ }^{2}$ Research Institute of Agricultural Economics (RIAE) is a predecessor of Institute of Agricultural Economics and Information (IAEI).

${ }^{3}$ CEPII - Centre d'Etudes Prospectives et d'Informations Internationales.
} 
defined by the $\mathrm{SIC}^{4}$ (code 20). According to Pierce and Schott's explanation (2009), SIC and HS codes cannot be matched directly due to the differences in how the two systems classify the products. Gálik (2013) refers to simplified classification of agrarian products based on 4-digit HS used by the Research Institute of Agriculture and Food Economics - RIAFE. Apparently, using 4-digit codes results in inaccurate categorization of some products. For instance, categorisation of rice (HS 1006) is problematic. Czech imports and exports contain husked semi-milled and wholly milled rice, which could be considered a processed product (of milling industry). Regarding fresh fruit within HS 0801-0806, a small proportion of dried fruits (for example raisins, bananas, and figs) is included in the RIAFE classification. In the period between 2004 and 2007, the Green reports of the CR contained categorization based on a 2 digit code. Chapters 01-14 of HS (Section I Live animals; animal products and Section II Vegetable products) were considered as unprocessed, and chapters 1524 (Section III Animal or vegetable fats and oils and their cleavage products; prepared edible fats; animal or vegetable waxes, Section IV Prepared foodstuffs; beverages, spirits and vinegar; tobacco and manufactured tobacco substitutes) as processed. The inaccuracy is obvious; meat and dairy products should not be classified as unprocessed products. In 2008, this indicative classification was abandoned.

Another source of differentiation of processed agrarian products proceeds from the NACE ${ }^{5}$. It is possible to consider products as processed when these are output of food and beverage industry, that is of NACE 10 and 11 divisions which correspond to the CPA ${ }^{6} 10$ and 11 divisions. Possibilities of actual convergence of $\mathrm{CN}$ and CPA were investigated by the Internal Research Project (IRP) no. 1290 ("Trends in the food market, food support system and the financial health of the food industry") in 2014 and, in more detail, only concerning the meat industry, as part of the IRP no. 1294 (,Meat - Strategy analysis of the meat processing industry in the Czech Republic") in 2015.

Generally, the following are the major disadvantages of the available types of classification:

- Excessive simplification which results in inaccurate assessment [categorization used by RIAFE, as well as Green News for the period between 2004 and 2007],

\footnotetext{
${ }^{4}$ SIC - Standard Industry Classification.

${ }^{5}$ NACE - Nomenclature générale des Activités économiques dans les Communautés Européennes (Statistical classification of economic activities)(EC, 2015).

6 CPA - Statistical Classification of Products by Activity in the European Economic Community (EC, 2015).
}

- Based on other than customs nomenclature, no conversion possible, let alone accurate (Lindland, 1997),

- The source list for commodities in individual categories is missing (Bereau et al., 2014; Henderson et al., 1996; Ratinger and Mathews, 1999),

- A higher number of categories or categories created using a different viewpoint than the degree of processing hinder interpretation and representation of (un)processed products (monthly analyses of EC (2004) as well as Regmi et al., 2005).

In fact, there are several methodologies related to attempts to evaluate the real state of added value distribution in relation to foreign trade performance. None of these is flawless. Each of the above methods is suitable for different purposes in understanding the commodity structure specifics. Czech authorities apply the methodology originally proposed by Regmi (2005) which, however, does not truly reflect the real state of the current commodity structure. The Research Institute of Agricultural Economics and Informatics is interested in developing its own method suitable for better understanding of the Czech agrarian foreign trade specifics. The objective of this paper is to specify the basic idea of the proposed methodology, to compare it with the already applied methodology and to present basic differences existing between the old and new approaches.

\section{Materials and methods}

The procedure for creating a new type of classification consists of:

- A decision made about its character and utilization.

- Examination of available types of classification and documents, and their comparison.

- Factual assessment of the degree of processing, experts' findings and present knowledge can also be considered.

- Analysis of Common Customs Tariff, that is of Customs Nomenclature ${ }^{7}$. Explanatory notes to the Harmonized System (HS) and to Combined Nomenclature $(\mathrm{CN})$ of EU, Changes in $\mathrm{CN}^{8}$ published by Czech

\footnotetext{
Customs Nomenclature uses Combined Nomenclature of the EU (8-digit codes). It is based on Harmonized Commodity Description and Coding System (2, 4 and 6-digit codes).

${ }^{8} \mathrm{CN}$ is revised to a certain degree every year. More considerable changes are managed in years when a revision of Harmonised system by the World Customs Organisation is performed (the latest in 2012).
} 
Customs Administration (2015) and official convertors between various nomenclatures determined by the Czech Statistical Office (for example, between $\mathrm{CN}$ and $\mathrm{CPA}^{9}$ ) have also been used.

Firstly, the decision has been made that the new classification should primarily serve the analyses of Czech foreign agrarian trade, therefore should be as specific and accurate as possible. Furthermore, the classification must incorporate chapters $01-24$ of the customs nomenclature, as agrarian products in all the IAEI reports on Czech agrarian foreign trade are defined accordingly.

Examination of the above types of classification reveals their drawbacks.

- Excessive simplification and subsequent imprecision of trade analysis thereof.

- Inapplicable for foreign trade data in customs nomenclature (no conversion possible).

- Missing source for the commodity (code) list.

- Different viewpoints regarding processing, too few or too many categories.

The factual assessment of products encounters a wide range of problems:

- It is necessary to determine which operation is and which is not considered processing (shelling, milling, drying, and other).

- Processing chains can be shorter for some commodities and longer for other; however, the same number of phases for all the products of HS 01-24 needs to be established.

- The margin between post-harvest handling and primary processing is not clear, what stage (shelling, milling, drying, and chilling/

9 CPA - Classification of Products by Activity. This product classification concerns activities as defined by NACE Rev. 2 (Classification of economic activities in the European Communities) (EC, 2015). freezing, among others) is relevant when determining the beginning of the process.

- Assessment of the degree of processing of the commodities produced in other areas and under different conditions and using different technology (coffee, tea, tobacco, fruit).

- The degree of processing might not reflect labour-intensity; livestock production is more labour-intensive than crop farming, even though live animals, along with cereals, are classified as an unprocessed raw material.

- Seeds and breeding animals are products with higher added value, although they are unprocessed and serve as production inputs.

- Processing can consist of sorting and packaging.

The nomenclature limitations are as follows:

- The customs nomenclature distinguishes products that are shelled, milled, dried, frozen, boned, etc. but does not include all the cases.

- Distinction of products per package size is sporadic.

- $\quad$ Some items (even 8-digit CN codes) include processed and unprocessed commodities (for example, fresh and dried fruits; often as part of less frequently traded items).

- It is not possible to determine (even using the Explanatory notes) what items are represented by "others".

- The convertors between nomenclatures are imperfect (however, should not be since various nomenclatures have different nature, purposes, and objects) (Figure 1).

Based on the examination of the available types of classification, assessment of the production

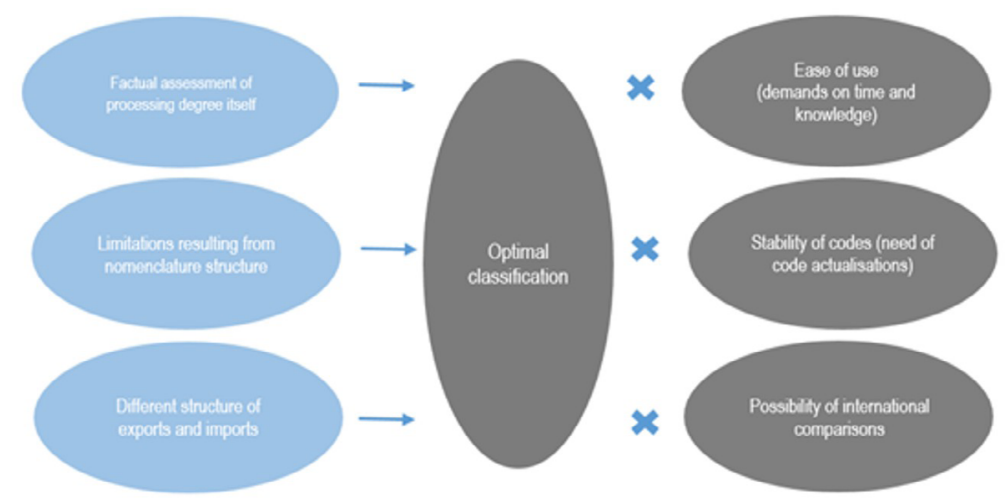

Source: Institute of Agricultural Economics and Information, 2018

Figure 1: Factors and implications of categorization. 
verticals and consideration of the customs nomenclature, three categories of products have been created: one containing unprocessed commodities and two with processed products - less and highly-processed (Figure 2).

A distinction between unprocessed and processed products has been primarily made by the fact that the product is output of food industry (or other, non-food, industry). The division of the products into less and highly processed is based on the numbers of the degree of processing. What has also been considered is whether the product is comprised of one or more raw materials as well as whether some input has already been processed. The newly proposed list of items under the individual categories is possible to find in appendix part this paper.

\section{Results and discussion}

1. Overview of the types of classification, their characteristics, strengths and weaknesses

\subsection{Currently used classification for assessment of Czech agrarian foreign trade (AFT)}

Since 2011, IEAI has been using classification based on Regmi et al. (2005) in its publications and agreement with the Ministry of Agriculture (20042007). It defines two categories of agricultural products that demonstrate dependence on soil and climatic conditions, and two categories of processed products independent of soil that can be produced under any conditions, the production of which chiefly requires technological knowhow, workforce and capital. Based on the classification, unprocessed commodities firstly consist of bulk commodities and secondly of horticultural products, including fruit and vegetable production. Both partially-processed (semifinished/intermediate)and processed products (those closest to the consumer and their "kitchen table") are regarded as products with a higher degree of processing (see appendix 1).

The classification derives from a maximum 6-digit HS code which enables international comparison; however, it is not sufficiently detailed. In addition, it is based on the definition of agricultural products by WTO - UK GATT Agricultural Agreement (that is, on the one hand, does not contain fish and seafood, and on the other, contains cotton, silk, furs and other commodities).

The major drawback lies in the fact that the semiprocessed products also include live animals. These are not dependent on soil, nevertheless, regarding the degree of processing, they could be considered a material.

IAEI uses the classification in a slightly modified form. First, some evident mistakes have been corrected, for instance, according to the materials available, aggregation HS 08119 ,other frozen fruit " is included in agricultural products, whereas the whole category HS 0811 "frozen fruit" is then mentioned in the processed products as well, or HS 1806 ,,chocolate and other preparations containing cocoa" is mistakenly mentioned in both semi-processed and highly-processed products. Furthermore, the item CN 04012099 , milk exceeding 3\% but not exceeding $6 \%$ of fat in maximum 2-litre packaging " has been moved from processed products into semi-processed. This was caused by the fact that the group also contains

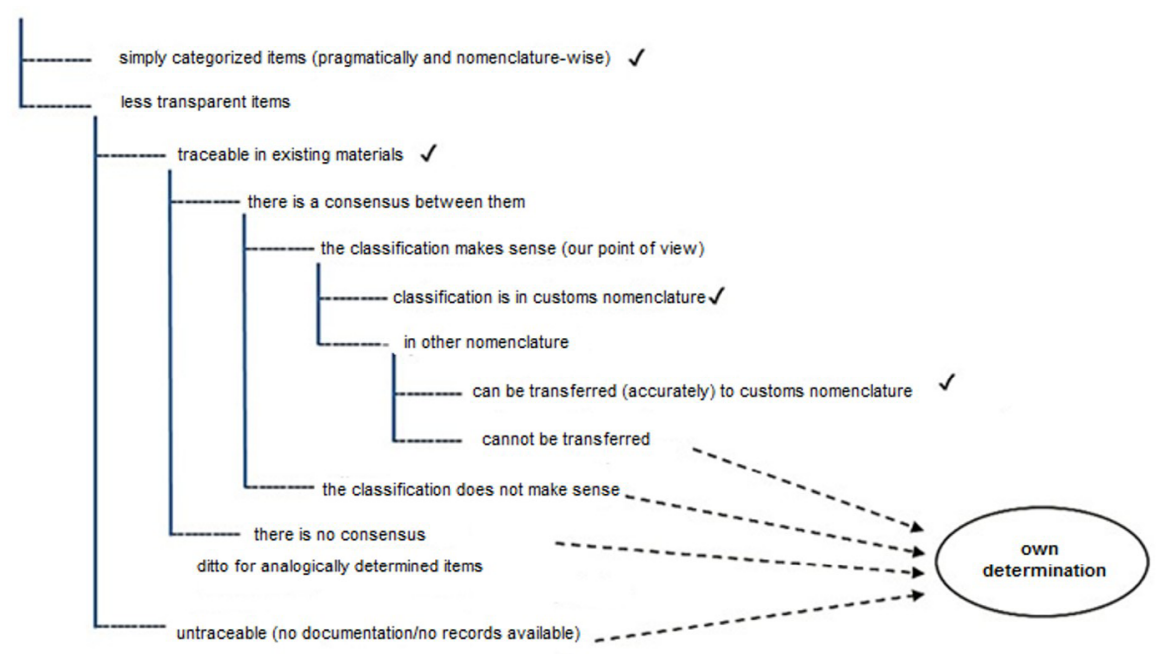

Source: Institute of Agricultural Economics and Information, 2018

Figure 2: General procedure for creating new classification. 
raw milk, which is one of the most significant commodities on the Czech export market, and results in considerable distortions.

Moreover, after reaching an agreement on AFT with the contracting authority at the Ministry of Agriculture, the classification was modified in order to include agrarian products specified in chapters HS 01-24. Items from other chapters have been excluded and some also amended.

\section{Disadvantages of classification:}

- The original classification was created for the commodities delimited by the Agricultural Agreement UK GATT, whereas IAEI has long-term used the traditional delimitation using chapters HS $01-24$ of the customs tariff.

- It derives from a maximum 6-digit HD code, that is from more general categorization, which is completely inadequate for some items.

- It concerns connection to soil more than to the degree of processing (for example, animals are thus considered semi-processed, or eggs in shells and honey are regarded as processed products).

- Publishing results without any commentary on the content of the given categories might be misleading.

- The original material (and other subsequent materials) contained evident, although less significant mistakes in the code list (code duplication in several categories).

\section{Advantages of classification:}

- Can be utilized for international comparison

- Already in effect (in the original form, for example, in some OECD materials) and is linked to other IAEI materials (Almanac and quarterly analyses of Czech AFT used since 2011).

- A clear code list and its simple use in data processing.

- Relative stability in time without any necessity to modify codes within the delimited categories.

\section{New classification}

\subsection{Specification of requirements for new classification}

The fundamental requirement for the new classification is based on the fact that it primarily and realistically needs to define the status and development of Czech agrarian foreign trade. The main purpose is to meet the demand for assessing Czech agrarian import and export. Therefore, international comparison is a less important criterion (other, less accurate types of classification can be used for year-on-year comparisons). The new classification also needs to include chapters HS 0124 of the customs tariff, since agrarian goods are defined accordingly in all the publications by IAEI discussing Czech AFT, which it should comply with.

Furthermore, three categories appear optimal: 1) unprocessed commodities, 2) less processed products and 3) highly processed products. Having two categories only seems inadequate, while assessment of AFT according to four and more categories might cause certain disorganization. The categories with less-processed and highlyprocessed products can be assessed separately or can be fused to one category with processed products. The previous IRP no. 1255/2016 mentions factors influencing the formation of classification, possibilities of factual delimitation of the degree of processing of agrarian commodities and limits of the customs nomenclature. This paper focuses on describing the methodology used when forming the new classification, both at a general level and for specific items. In the majority of cases, scheme 1 was followed to categorize the items.

\subsection{Own categorization}

The dividing line between processed and unprocessed products has predominantly been given by the fact whether the product is the output of one of food (or other) industries. If it is, the product is considered processed. In this regard, the research follows IRP No. 1290/2014 and $1294 / 2015$ conducted by IAEI. The distinction between less and highly processed products normally depends on the number of degrees of processing that the products have undergone. In addition, what has been considered is whether the product derives from one or more raw materials or whether any of the raw materials have been processed or not. This matter concerns, for instance, sugar, regarding which the customs tariff distinguishes a number of commodities, with and without added sugar. For example, dairy products with added sugar are automatically regarded as highly processed products in the research. It is necessary to state that simplification cannot be avoided when classifying items into the defined categories even though certain logic has been respected. Since the categorized products are heterogeneous, 
the procedure mentioned cannot be applied to all the items without exceptions.

\subsubsection{Unprocessed commodities}

Live animals (as well as fish and aquatic invertebrates) are regarded as unprocessed commodities and raw materials intended for subsequent processing or production. This also refers to pure-bred breeding animals, although these are commodities with more added value traded at higher unit prices. Similarly, cereal and oil crops, and seeds are also considered unprocessed. What needs to be added is that cereal and oil crops for seeding are assessed separately in the customs tariff only when this concerns their most important varieties, therefore, in a number of cases, it would be impossible to distinguish them from common cereal or oil crops. Eggs in shells are regarded as unprocessed commodities, although they are further classified as packed and sold in the same state to the end customer. Both immature and mature legumes are considered unprocessed commodities. The fact that they can be shelled or split is thus disregarded, as the customs tariff does not enable this. Like cereal crops, drying of legumes is regarded as post-harvest treatment. Their shelling usually takes place on the field and is a part of the harvest. According to the classification in this paper, unprocessed commodities also contain fresh potatoes, vegetables, fruit and nuts, and other plant products from commodity aggregation $H S 1212$, except for sugar beet, dried (or in the powder form), kelp and other types of seaweed (which, presumably, appear on the market in a modified form). The aggregations HS 1212 mentioned in some items are included as both unprocessed and processed at a detailed level, however, overall, in terms of trade, these are minority goods. Regarding spices, the uncrushed / unground have been incorporated in the unprocessed commodity category. The size and the method of packing is determined by the customs tariff only regarding an insignificant number of commodities, which is the reason why this criterion was not considered for classification (it would be impossible to use). In addition, with the majority of the products, the packaging size would not influence the perception of their degree of processing. Dairy products and tea were exceptions, and their packaging was considered. Item CN 04012099 ,,milk exceeding $3 \%$ but not exceeding $6 \%$ of fat in packaging exceeding 2 litres " is regarded as a raw material owing to the fact that it mainly contains raw milk. It represents a very important $\mathrm{Czech}$ export product, while it is less significant in import. The nomenclature distinguishes between black and green tea and, in both cases, it is divided into packets not exceeding $3 \mathrm{~kg}$ and exceeding $3 \mathrm{~kg}$. The former is considered semi-processed (teabags, packed), whereas the latter is categorized into unprocessed commodities. Fermentation is not perceived as a processing phase. Regarding coffee, the size of packaging is not considered by the customs tariff. The only distinction is made between roasted and unroasted coffee, with and without caffeine. This research considers only unroasted caffeinated coffee as unprocessed. Regarding cocoa beans, the nomenclature does not distinguish raw and roasted beans, therefore they are all defined as unprocessed. Unprocessed tobacco and tobacco waste, although dried, is also regarded as a raw material and an unprocessed commodity. The unprocessed commodity category also contains straw and chaff, feeding roots, shellac, natural rubber, resin and other commodities (HS 1301), plant fibres and plant products not mentioned elsewhere, raw plant and insect wax, which are insignificant in terms of trade. Regarding beverages, unsweetened water (KN 220190 00) has been categorized into unprocessed commodities, which also include ordinary water.

\subsubsection{Less processed products}

With some commodities, peeling, crushing/ grinding, drying and freezing are considered partial processing. Regarding vegetables and fruit, drying and freezing are considered primary types of processing as they usually require preparation stages such as sorting, washing, or cutting and similar activities. The varieties of fruit which commonly appear in a dried form are classified and distinguished separately as fresh and dry by the customs tariff. The fruit that does not enable distinction between its dried and fresh parts (for instance, dates, pineapple or citrus fruits) is categorized into unprocessed commodities (it is presumed that the dried part is less significant and is traded less frequently in this form). In accordance with the majority of the remaining types of classification, a distinction is also made with nuts and spices as to whether these are shelled or crushed / ground / in a powder form. The items that started to be considered unprocessed and processed by the nomenclature at a later stage (for example, some nuts or spices as late as after 2012) were, in the years when this did not occur, categorized based on the form they were traded in when the information was available. It is possible to determine the contribution of the commodities that were traded both in their unprocessed and processed form, however, the importance of these is insignificant; therefore, each item 
was included in the one with greater importance. Exceptionally, the level of classification in the customs tariff declined over the years (this signifies that, due to low importance, the codes were gradually removed).

Moreover, mill products (which represent the first stage of processing cereal crops, legumes, root and tuber crops), malt and starch, decorticated oil crops, provided that decortication occurs, and the customs tariff identifies this, as well as flour and semolina from oil seeds were categorized into less-processed products. Oils and fats, sugar excluding additives and dyes, treacle and cocoa products after the first stage of processing, including cocoa powder (only that excluding added sugar) are also regarded as less-processed products. Regarding animal products, meat (while taking into consideration that it might be in the form of either half carcass for further processing or boned and intended for the consumer), offal and fat have been classified into the lessprocessed category of commodities. Concurrently, only fresh meat, refrigerated or frozen, is regarded as a less processed product. A similar procedure was followed with fish and aquatic invertebrates, while taking into consideration that the whole fish (which does not enable distinction as to whether they are disembowelled or not) were classified into this category along with fish meat. Regarding dairy products, those not marked by a higher number of processing phases have been included in the less processed. Eggs without shells are another type of less processed products.

\subsubsection{Highly processed products}

Meat products as well as meat that have undergone another phase of processing (such as drying, salting, smoking) are considered as highly processed products. Fish products have also been classified similarly. Regarding dairy products, those that have undergone more production operation processes as well as those containing added sugar have been classified into this category. The majority of other products included in this category are found in the chapters with higher numbers, which usually contain food products. This concerns for example white sugar and confectionery, food preparations containing cocoa (for example chocolate), cereal crop products (pasta, bakery products and other commodities), fruit and vegetable products or other food products. Alcoholic and non-alcoholic beverages and cigarettes are regarded as highlyprocessed products.

\section{Disadvantages of classification:}

- Requires more frequent updates of codes in individual categories due to the fact that more frequent changes occur at a more detailed commodity level which need to be considered in classification.

- Processing data from other databases than that of CSO is time-consuming.

- More thorough processing is required in connection with more extensive code lists in individual categories.

- Less suitable for international comparison.

\section{Advantages of classification:}

- Provide a more realistic overview of Czech AFT in terms of assessing the degree of processing of commodities.

- The degree of processing of commodities is the main criterion.

- The data from CSO, with the code lists updated regularly, are relatively easy to process and enable regular publication.

\section{Comparison of old and new classification}

\subsection{Currently used classification for assessment of Czech AFT by Regmi et al. (2005)}

- 4 product categories - bulk commodities, horticultural products, semi-processed products and highly-processed products.

- Derives from HS nomenclature (maximum 6-digit HS codes).

- The original classification incorporating agrarian goods defined by WTO had to be adjusted in order to consider customs tariff chapters HS 01-24.

- The category with bulk commodities and horticultural products is well-interpretable.

- Only plant commodities are considered as unprocessed.

- Horticultural products also contain those that are partially processed (ground, crushed, dried).

- The name of the category of semi-processed products is misleading as it contains raw materials as well.

- Semi-processed products contain live animals (HS 0101 to 0106), dried legumes (HS 0713), seeds, fruit and spores for planting (HS 1209) or straw and chaff 
(HS 1213), and fodder crops (HS 1214).

- (Highly) processed products contain honey (HS 0409) or eggs in shells (HS 0407). The original classification by Regmi et al. (2005) also contained raw milk.

\subsection{New classification}

- 3 product categories - unprocessed commodities, less-processed products and highly-processed products.

- Uses CN nomenclature (up to 8-digit $\mathrm{CN}$ codes), more detailed.

- Incorporates customs tariff chapters HS 01-24.

- Live animals are considered a raw material. Breeding animals are classified into unprocessed.

- Grinding, crushing, drying and freezing are considered as processing phases with the majority of commodities.

4 Comparison of analysis of Czech AFT according to the degree of processing of commodities based on old and new classification

This concerns the structure of Czech agrarian export, import and the balance between 2011 and 2016 within AFT overall, both with EU 28 and the third countries, according to both old and new classification. The unprocessed and highly processed commodity categories are compared as they are the closest in both types of classification in terms of their nature and definition.

4.1 Analysis of Czech agrarian export and import based on the degree of processing of commodities

In 2016, the contribution of unprocessed products ${ }^{\mathbf{1 0}}$ to Czech agrarian export, including ,tobacco and tobacco products" using the old classification is lower than using the new methodology (15\% vs $22 \%$ ), please see tables 1 and 2 below. Regarding import, the contribution amounted to $21 \%$ using both old and new classification. This signifies that, using the old classification, the representation of unprocessed commodities in export in comparison with import was considerably lower, whereas it was slightly higher using the new methodology. The contribution of unprocessed products to export using both the old and the new methodology has been on the decrease since

\footnotetext{
10 That is, considering old classification, the sum of two categories - bulk commodities and horticultural products, while considering the new classification, of one category with unprocessed commodities.
}

2011, at a similar rate. In terms of import, it was on the decrease until 2014 (at the same rate, using both old and new methodologies), and subsequently developed identically. Using the old methodology, the contribution of the highly processed product category including, ,tobacco and tobacco products“ to Czech agrarian export in 2016 was $62 \%$, while using the new methodology it reached $54 \%$ (that is to a lesser degree using the new classification). Regarding import, their contribution amounted to $64 \%$ using the old methodology and $46 \%$ using the new one (that is, using the new classification, equally to a lesser degree). Using the old methodology, the contribution of highlyprocessed products was slightly higher concerning import, while using the new methodology it was higher regarding export. Since 2011, using old and new methodologies, the development of the contribution to both export and import has been similar. No upward or downward trend is evident (almost no change is evident) (Table 1,2).

Assessment of the structure of Czech AFT according to the degree of processing of commodities differs relatively significantly depending on whether this concerns trade with EU 28 or with the third countries, please see Tables 3 and 4.

Regarding export, an identical difference was recorded in 2016 using both types of classification (assessed in percentage points) in the representation of unprocessed commodities. Regarding Czech agrarian export to the third countries, the contribution of these commodities was $7 \mathrm{pp}$ lower than to the European Union. A contrary difference is subsequently evident in the case of export in the representation of highlyprocessed products. Using the old classification, the contribution of Czech agrarian export to the third countries is $3 \mathrm{pp}$ higher than to the European Union, whereas using the new classification it exceeds $10 \mathrm{pp}$.

Regarding import (HS 01-24) and using the old classification, the contribution of unprocessed products to Czech AFT with the third countries in 2016 was 23 pp higher than with EU 28, while using the new methodology it exceeded $16 \mathrm{pp}$. Using both old and new classification, the representation of highly-processed products in AFT outside EU in comparison with trade with EU decreased, namely by $21 \mathrm{pp}$ in the first case, and by $17 \mathrm{pp}$ in the second. 


\begin{tabular}{|l|l|r|r|r|r|r|r|}
\hline & Category & $\mathbf{2 0 1 1}$ & $\mathbf{2 0 1 2}$ & $\mathbf{2 0 1 3}$ & $\mathbf{2 0 1 4}$ & $\mathbf{2 0 1 5}$ & $\mathbf{2 0 1 6}$ \\
\hline \multirow{5}{*}{ Export } & Bulk commodities & 14 & 14 & 13 & 12 & 12 & 11 \\
\cline { 2 - 8 } & Horticultural products & 5 & 4 & 5 & 4 & 4 & 4 \\
\cline { 2 - 8 } & Unprocessed commodities & $\mathbf{1 8}$ & $\mathbf{1 9}$ & $\mathbf{1 8}$ & $\mathbf{1 7}$ & $\mathbf{1 7}$ & $\mathbf{1 5}$ \\
\cline { 2 - 8 } & Semi-processed products & 21 & 23 & 23 & 23 & 22 & 23 \\
\cline { 2 - 8 } & Highly-processed products & 61 & 59 & 59 & 60 & 61 & 62 \\
\cline { 2 - 8 } & Processed products & $\mathbf{8 2}$ & $\mathbf{8 1}$ & $\mathbf{8 2}$ & $\mathbf{8 3}$ & $\mathbf{8 3}$ & $\mathbf{8 5}$ \\
\hline \multirow{5}{*}{ Import } & Bulk commodities & 6 & 7 & 6 & 6 & 5 & 5 \\
\cline { 2 - 8 } & Horticultural products & 16 & 15 & 15 & 15 & 15 & 16 \\
\cline { 2 - 8 } & Unprocessed commodities & $\mathbf{2 2}$ & $\mathbf{2 1}$ & $\mathbf{2 1}$ & $\mathbf{2 0}$ & $\mathbf{2 0}$ & $\mathbf{2 1}$ \\
\cline { 2 - 8 } & Semi-processed products & 14 & 14 & 15 & 15 & 15 & 15 \\
\cline { 2 - 8 } & Highly processed products & 64 & 65 & 64 & 64 & 64 & 64 \\
\cline { 2 - 8 } & Processed products & $\mathbf{7 8}$ & $\mathbf{7 9}$ & $\mathbf{7 9}$ & $\mathbf{8 0}$ & $\mathbf{8 0}$ & $\mathbf{7 9}$ \\
\hline
\end{tabular}

Source: Foreign trade database of CSO, data ,without additional calculations“", 2018

Table 1: Structure of Czech AFT overall based on the degree of processing of commodities using the old methodology (in \%)

\begin{tabular}{|l|l|c|r|r|r|r|c|}
\hline & Category & $\mathbf{2 0 1 1}$ & $\mathbf{2 0 1 2}$ & $\mathbf{2 0 1 3}$ & $\mathbf{2 0 1 4}$ & $\mathbf{2 0 1 5}$ & $\mathbf{2 0 1 6}$ \\
\hline \multirow{5}{*}{ Export } & Unprocessed commodities & $\mathbf{2 7}$ & $\mathbf{2 7}$ & $\mathbf{2 6}$ & $\mathbf{2 5}$ & $\mathbf{2 4}$ & $\mathbf{2 2}$ \\
\cline { 2 - 8 } & Less processed products & 22 & 24 & 24 & 25 & 26 & 24 \\
\cline { 2 - 8 } & Highly processed products & 50 & 49 & 50 & 50 & 50 & 54 \\
\cline { 2 - 8 } & Processed products & $\mathbf{7 3}$ & $\mathbf{7 3}$ & $\mathbf{7 4}$ & $\mathbf{7 5}$ & $\mathbf{7 6}$ & $\mathbf{7 8}$ \\
\hline \multirow{6}{*}{} & Unprocessed commodities & $\mathbf{2 2}$ & $\mathbf{2 2}$ & $\mathbf{2 1}$ & $\mathbf{2 0}$ & $\mathbf{2 0}$ & $\mathbf{2 1}$ \\
\cline { 2 - 8 } & Less processed products & 31 & 31 & 32 & 34 & 35 & 33 \\
\cline { 2 - 8 } & Highly processed products & 47 & 47 & 47 & 46 & 45 & 46 \\
\cline { 2 - 8 } & Processed products & $\mathbf{7 8}$ & $\mathbf{7 8}$ & $\mathbf{7 9}$ & $\mathbf{8 0}$ & $\mathbf{8 0}$ & $\mathbf{7 9}$ \\
\hline
\end{tabular}

Source: Foreign trade database of CSO, data „without additional calculations“.

Table 2: Structure of Czech AFT based on the degree of processing of commodities using the new methodology (in \%), with tobacco and tobacco products.

\begin{tabular}{|l|l|c|c|c|c|c|c|}
\hline \multirow{5}{*}{} & \multirow{2}{*}{ Category } & \multicolumn{2}{|c|}{ AFT overall } & \multicolumn{2}{c|}{ with EU 28 } & \multicolumn{2}{c|}{ With third countries } \\
\cline { 3 - 8 } & & $\begin{array}{c}\text { with } \\
\text { HS 24 }\end{array}$ & $\begin{array}{c}\text { without } \\
\text { HS 24 }\end{array}$ & $\begin{array}{c}\text { with } \\
\text { HS 24 }\end{array}$ & $\begin{array}{c}\text { without } \\
\text { HS 24 }\end{array}$ & $\begin{array}{c}\text { with } \\
\text { HS 24 }\end{array}$ & $\begin{array}{c}\text { without } \\
\text { HS 24 }\end{array}$ \\
\hline \multirow{5}{*}{ Export } & Bulk commodities & 11 & 12 & 11 & 13 & 4 & 4 \\
\cline { 2 - 9 } & Horticultural products & 4 & 5 & 4 & 5 & 4 & 5 \\
\cline { 2 - 9 } & Unprocessed commodities & $\mathbf{1 5}$ & $\mathbf{1 7}$ & $\mathbf{1 5}$ & $\mathbf{1 7}$ & $\mathbf{8}$ & $\mathbf{9}$ \\
\cline { 2 - 9 } & Semi-processed products & 23 & 26 & 23 & 26 & 27 & 29 \\
\cline { 2 - 9 } & Highly-processed products & 62 & 57 & 62 & 57 & 65 & 62 \\
\cline { 2 - 9 } & Processed products & $\mathbf{8 5}$ & $\mathbf{8 3}$ & $\mathbf{8 5}$ & $\mathbf{8 3}$ & $\mathbf{9 2}$ & $\mathbf{9 1}$ \\
\hline \multirow{5}{*}{ Import } & Bulk commodities & 5 & 4 & 4 & 4 & 10 & 7 \\
\cline { 2 - 9 } & Horticultural products & 16 & 17 & 14 & 14 & 31 & 32 \\
\cline { 2 - 9 } & Unprocessed commodities & $\mathbf{2 1}$ & $\mathbf{2 1}$ & $\mathbf{1 8}$ & $\mathbf{1 8}$ & $\mathbf{4 1}$ & $\mathbf{3 9}$ \\
\cline { 2 - 9 } & Semi-processed products & 15 & 16 & 16 & 17 & 14 & 14 \\
\cline { 2 - 9 } & Highly processed products & 64 & 63 & 67 & 65 & 46 & 47 \\
\cline { 2 - 8 } & Processed products & $\mathbf{7 9}$ & $\mathbf{7 9}$ & $\mathbf{8 2}$ & $\mathbf{8 2}$ & $\mathbf{5 9}$ & $\mathbf{6 1}$ \\
\hline
\end{tabular}

Source: Foreign trade database of CSO, data ,without additional calculations“, 2018

Table 3: Structure of Czech AFT according to the degree of processing of commodities using the old methodology (in \%), in 2016, in terms of territory 


\begin{tabular}{|l|l|c|c|c|c|c|c|}
\hline \multirow{5}{*}{} & Category & \multicolumn{2}{|c|}{ AFT overall } & \multicolumn{2}{c|}{ with EU 28 } & \multicolumn{2}{c|}{ with third countries } \\
\cline { 3 - 8 } & & $\begin{array}{c}\text { with } \\
\text { HS 24 }\end{array}$ & $\begin{array}{c}\text { without } \\
\text { HS 24 }\end{array}$ & $\begin{array}{c}\text { with } \\
\text { HS 24 }\end{array}$ & $\begin{array}{c}\text { without } \\
\text { HS 24 }\end{array}$ & $\begin{array}{c}\text { with } \\
\text { HS 24 }\end{array}$ & $\begin{array}{c}\text { without } \\
\text { HS 24 }\end{array}$ \\
\hline \multirow{5}{*}{ Export } & Unprocessed commodities & $\mathbf{2 2}$ & $\mathbf{2 5}$ & $\mathbf{2 3}$ & $\mathbf{2 6}$ & $\mathbf{1 6}$ & $\mathbf{1 8}$ \\
\cline { 2 - 8 } & Less processed products & 24 & 27 & 25 & 27 & 21 & 23 \\
\cline { 2 - 8 } & Highly processed products & 54 & 49 & 53 & 47 & 63 & 60 \\
\cline { 2 - 9 } & Processed products & $\mathbf{7 8}$ & $\mathbf{7 5}$ & $\mathbf{7 7}$ & $\mathbf{7 4}$ & $\mathbf{8 4}$ & $\mathbf{8 2}$ \\
\hline \multirow{5}{*}{ Import } & Unprocessed commodities & $\mathbf{2 1}$ & $\mathbf{2 1}$ & $\mathbf{1 8}$ & $\mathbf{1 9}$ & $\mathbf{3 4}$ & $\mathbf{3 2}$ \\
\cline { 2 - 9 } & Less processed products & 33 & 35 & 33 & 34 & 35 & 36 \\
\cline { 2 - 9 } & Highly processed products & 46 & 44 & 48 & 47 & 31 & 32 \\
\cline { 2 - 9 } & Processed products & $\mathbf{7 9}$ & $\mathbf{7 9}$ & $\mathbf{8 2}$ & $\mathbf{8 1}$ & $\mathbf{6 6}$ & $\mathbf{6 8}$ \\
\hline
\end{tabular}

Source: Foreign trade database of CSO, data ,without additional calculations“.

Table 4: Structure of Czech AFT according to the degree of processing using the new methodology (in \%), in 2016, in terms of territory

\subsection{Czech AFT balance analysis based on the degree of processing of commodities}

The balance of the overall Czech AFT regarding chapters HS 01-24 with unprocessed commodities using the old classification is negative and amounted to 16 billion CZK in 2016. In comparison with 2011, it was $44 \%$ higher (considering the fact that between 2012 and 2014 the deficit did not exceed 10 million CZK). In the trade with EU 28 (HS 01-24) in the monitored period 2011-2016, the development concerning unprocessed commodities was similar, while the deficit in 2016 amounted to 4.9 billion CZK (although the lowest liability was reported in 2014 , and not in the overall trade in 2012). Regarding trade with the third countries (HS 01-24) and unprocessed commodities and using the old classification, it might be concluded that the deficit value was on the increase (with more regular development than regarding trade with EU) and amounted to 11.2 billion CZK in 2016. Excluding ,tobacco and tobacco products“ (that is excluding chapter $H S$ 24), a difference is evident in the development in the Czech agrarian trade with EU 28. In 2016, the deficit in the trade with unprocessed commodities amounted to 4.3 billion CZK using the old classification, nevertheless, in 2012, 2014 and 2015 the balance was active (maximum 1.1 billion CZK in 2015).

Using the new classification, the balance of Czech AFT with unprocessed commodities (HS 01-24) changed twice, from negative in 2011 to positive in the following four years and, subsequently, to negative in 2016, after a sharp year-on-year decline, to level 1.4 billion CZK. Excluding the chapter HS 24, the direction of the development during the monitored period was similar, however, in 2016 the balance remained slightly positive (168 mil. CZK). Regarding unprocessed commodities (za HS 01-24), the development of the trade balance with EU 28 was similar to that overall, although its value remained active in the entire period. In 2016, the active balance amounted to 6.3 billion CZK (and, excluding $H S 24$, to 6.9 billion $\mathrm{CZK}$ ). Regarding the third countries, the balance of the trade with unprocessed commodities is passive using the new classification (HS 01-24). The value of the deficit until 2015 oscillated between $6.6-7.0$ billion CZK, however, in 2016 it increased considerably year on year, namely to 7.7 billion CZK (excluding chapter $H S$ 24, to 6.7 billion CZK).

Concerning highly processed products and using the old classification, the long-term negative balance of Czech AFT of chapters HS 01-24 between 2011 and 2016 gradually decreased by $32 \%$ to 17.4 billion CZK. In the trade with EU 28 (HS 01-24), the declining trend in the deficit was slightly more irregular, and its value between 2011 and 2016 increased by $36 \%$ to 13.2 billion CZK. The value of passive balance of trade with the third countries in highly processed products (HS 01 24) does not demonstrate any trend, the deficit oscillated between 2.6 and 4.6 billion CZK, while in 2016 it amounted to 2.9 billion $\mathrm{CZK}$. When excluding, tobacco and tobacco products" from agrarian goods, the negative balance in highly processed products using the old classification within the overall Czech AFT, but also within the trade with EU 28, developed differently (its development was irregular). In the first case, in 2016, the overall AFT amounted to 29.3 billion CZK (and remained practically unchanged against 2011), whereas in the second, in trade with EU, it reached 23.9 billion $\mathrm{CZK}$ (that is $3.7 \%$ less than 
in 2011). Using the old classification, regarding the trade in highly processed products with the third countries and excluding chapter $H S 24$, the deficit oscillated between 2.9 and 6.0 billion CZK (in 2016 it amounted to 4.1 billion CZK).

Using the new classification, the balance of the overall Czech AFT in highly processed products ( $H S 01$ 24) in the period between 2011 and 2016 also improved. In 2015, its value even changed from passive to active, and in 2016 reached 4.1 billion CZK. Regarding trade with EU 28 and using the new classification (HS 01-24), the status changed as early as in 2014. In 2016, the active balance amounted to 4.7 billion CZK and the positive balance of Czech AFT with the third countries in highly processed products incorporated in the new classification (HS 01-24) amounted to 1.2 billion CZK (while in 2011, it was still negative and reached 2.6 billion CZK). In the entire monitored period, excluding ,tobacco and tobacco products", the balance of Czech agrarian trade in highly processed products using the new classification both with EU and with the third countries was negative. Concerning overall AFT in 2016, the balance deficit amounted to 6.6 billion CZK and against EU to 6.4 billion CZK. However, in both cases its value in the monitored years improved, that is it was on the decrease. Regarding the third countries, the development of the deficit recorded year-on-year fluctuations against these, while considering the fact that in 2016 it amounted to minimum 42 mil. CZK, that is the balance was almost level. The above significant differences between the balances in the monitored categories are levelled by the remaining categories. The balance of the trade in semi-processed products, that is the category in the old classification, is fairly active - for example, in 2016 within the Czech AFT (HS 01-24) it amounted to 11.9 billion CZK, while the balance of the trade in less-processed products, that is the category in the new classification, is highly negative - in 2016 in the overall Czech AFT (HS 01-24) it amounted to 24.2 billion CZK.

\section{Conclusion}

Classification of agrarian goods into three categories is considered the most suitable, namely into unprocessed commodities, less processed products and highly processed products. When forming the categories, the priority was given to the degree of processing over, for instance, added value or laboriousness. When classifying the commodities into the defined categories, a combination of assessment of the commodity in terms of the degree of processing as well as of how it is treated in other available types of classification has been applied. The final classification is thus influenced by the customs nomenclature and its possibilities. The research also states the reasons why, when analysing Czech AFT, it is not suitable to use the presently-used and adjusted classification by Regmi et al. (2005), nor its strengths and weaknesses. Furthermore, it also mentions that it is necessary to create new classification that would involve the degree of processing in Czech export and import more effectively. Such classification could then become a part of assessment of Czech AFT by IAEI. Despite repeated revisions made in 2017 in the product lists created in individual categories, no alterations have been made in the classification created as part of IRP in 2016. However, the new classification has been interpreted again and more effectively, while this concerns both general methodology and specific categorization of individual commodities. It is the presentation of the methodology that has improved, rather than the methodology itself. The main reason why the first goal of the internal project was not achieved to the full extent was failure in establishing planned cooperation with a partner at CULS due to time and capacity. Nevertheless, a joint paper should be completed next year. In order to assess Czech AFT according to the degree of processing of commodities, that is to create the new classification, an 8-digit level of the EU nomenclature was used, although such classification requires more frequent updates and does not enable international comparison outside EU countries or the countries the foreign trade of which is monitored by Eurostat (that is the countries of the European Free Trade Association and those in the Western Balkans, as well as the candidate countries which provide data about their foreign trade based on $\mathrm{CN}$ ). For this purpose, one of the existing types of classification deriving from the Harmonised system of description and from product coding (although HS level is completely insufficient for more accurate assessment of Czech AFT) would have to be used. Regarding comparison within EU, some distortion might be caused by the fact that categorization of some commodities in order to monitor Czech AFT might not correspond with the trade reality of other countries. The code listsincluded in the research can be used only in the CSO database of foreign trade, nevertheless, the attached code lists in individual categories also enable to process Eurostat data. The major disadvantage 
is that the process is time-consuming. In regard to receiving more regular information, receiving data from the database could possibly be automated. A regular revision is an essential prerequisite for using the newly-created classification. More frequent and necessary updates involve regular annual assessment of changes in the customs tariff (that is checking whether these are reflected in the classification) and their transfer to the code list. No future changes or estimation of the development of the nature of the goods nor the range in the customs codes have been considered beforehand in the currently created classification. It is presumed that the prospective development in this regard can be projected in the code list at a later stage without any major disruptions in comparison in time. This derives from the assumption that if some codes currently contain mainly unprocessed products, they should be included in the unprocessed, and if they contain mainly processed items, they should be included in the processed (this way they will reflect the state of Czech AFT based on the degree of processing of commodities adequately). However, this requires continuous monitoring of the issue. For the future, it would be suitable to propose implementation of the new methodology to the Ministry of Agriculture to the contracting party determining the assignments related to Czech AFT. Any adjustments to the classification suggested by the opponents of this project and by potential users of the outcome can be negotiated. Based on the research, it is recommended that the issue remains the focus of attention. There have not been almost any changes in the references. Those that serve as sources for the available classification have been retained, and other, newly used, have been added. Some documents and links to these (referring mainly to customs nomenclature) have been updated.

\section{Acknowledgements}

The paper was supported by the internal development project (IDP n. 1111) provided by the Institute of Agricultural Economics and Information.

Corresponding authors:

prof. Ing. Luboš Smutka, Ph.D.

Department of Economics, Faculty of Economics and Management

Czech University of Life Sciences Prague, Kamýcká 129, 16500 Prague - Suchdol, Czech Republic

E-mail:smutka@pef.czu.cz

\section{References}

[1] Bureau, J.-Ch., Disdier, A.-C., Emlinger, Ch., Fouré. J., Felbermayr, G., Fontagné, L. and Jean, S. (2014) "Risks and opportunities for the EU agri-food sector in possible EU-US trade agreement", Study IP/B/AGRI/IC/2013_129 for the European Parliament. Brussels. [Online]. Available: http://www.europarl.europa.eu/RegData/etudes/STUD/2014/514007/AGRI_IPOL_ STU(2014)514007_EN.pdf. [Accessed: 15 Dec. 2017].

[2] Burianová, J. (2011a) "Effect of the 2008-2009 economic crisis on the results of agricultural foreign trade of the Czech Republic", Agricultural economics - Zemědělská ekonomika, Vol. 57, No. 5, pp. 226-231. ISSN 0139-570X.

[3] Burianová, J. (2011b) "Agrarian foreign trade of the Czech Republic in the period of 2004-2008, competitiveness of commodities", Acta Universitatis Agriculturae et Silviculturae Mendelianae Brunensis, Vol. 59, No. 4, pp. 37-42. ISSN 1211-8516. DOI 10.11118/actaun201159040037.

[4] Customs Administration of the Czech Republic (2015) "Změny kombinované nomenklatury" (Changes of the CN since 2007) (In Czech), Work aid. Customs Administration of the Czech Republic. General Directorate of Customs. [Online]. Available: https://www.celnisprava.cz/cz/clo/ sazebni-zarazeni-zbozi/spolecny-celni-sazebnik-es/Spolen\%20celn\%20sazebnk\%20ES\%202015/ Korelace2015.pdf. [ Accessed: 17 May 2016].

[5] Čermák, M., Malec, K. and M. Maitah. (2017) „Price Volatility Modelling-Wheat: GARCH Model Application“, Agris on-Line Papers in Economics and Informatics, Vol. 9, No. 4, pp. 15-24. ISSN 1804-1930. DOI 10.7160/aol.2017.090402.

[6] European Commision (2015) "Agri-food trade presentation - details of the 6 classes of products", Directorate General for Agriculture and Rural Development [Online]. Available at: https://ec.europa. eu/agriculture/sites/agriculture/files/trade-analysis/statistics/outside-eu/2015/product-classesdetails_en.pdf [Accessed: 15 Nov. 2017]. 
[7] European Commision (2015) "Common tariff of the EU. For 2016: Commission Implementing Regulation (EU) No 1754/2015", Official Journal of the EU L 285. [Online]. Available: https://publications.europa.eu/en/publication-detail/-/publication/d20e7f04-7ed4-11e5-b8b701aa75ed71a1 [Accessed: 17 May 2018].

[8] European Commision (2015) "Explanatory Notes to the Combined Nomenclature of the European Union (2015/C 076/01)", Official Journal of the EU C 76, Vol. 58. [Online] Available: http://eurlex.europa.eu/legal-content/EN/TXT/PDF/?uri=OJ:C:2015:076:FULL\&from=EN [Accessed: 7 Nov. 2017].

[9] European Commission (2014) "Agricultural trade statistics 2005 - 2014". [Online]. Available: https://https://ec.europa.eu/agriculture/statistics/trade/2014_en [Accessed: 10 May 2018].

[10] FAO (1994) "Definition and Classification of Commodities", FAO, Rome. [Online]. Available: http://www.fao.org/waicent/faoinfo/economic/faodef/faodefe.htm [Accessed: 15 May 2018].

[11] Gálik, J. (2013) "Agrarian foreign trade book of the Slovak Republic 2012", RIAFE. Bratislava. ISBN 80-7137-722-8.

[12] Henderson, D. R., Sheldon, I. M. and Pick, D. H. (1996) "International commerce in processed foods: Patterns and curiosities", Working paper 96-3, International Agricultural Trade Research Consortium. [Online]. Available: https://ageconsearch.umn.edu/bitstream/51211/2/96-3.pdf [Accessed: 15 Nov. 2017].

[13] Honig, V., Procházka, P., Linhart, Z. and Smrčka, L. (2018) "Effect of tax policy changes on bioethanol market", Listy cukrovarnické a řepařské, Vol. 134, No. 2, pp. 74-78. ISSN 1210-3306.

[14] Liapis, P. (2011) "Changing Patterns of Trade in Processed Agricultural Products", OECD Food, Agriculture and Fisheries Working Papers No. 47. OECD Publishing. [Online] Available: https://www.oecd-ilibrary.org/docserver $/ 5 \mathrm{kgc} 3 \mathrm{mq} 19 \mathrm{~s} 6 \mathrm{~d}$-en.pdf?expires= $1531302597 \& \mathrm{id}=\mathrm{id} \&$ accname $=$ guest $\&$ checksum $=5$ BABEEA5AB38B90A54CE9C7375D3D761 [Accessed: 6 Nov. 2017].

[15] Lindland, J. (1997) "The Impact of the Uruguay Round on Tariff Escalation in Agricultural Products", ESCP, No. 3, FAO. [Online] Available: http://www.fao.org/3/a-w4357e.pdf [Accessed: 6 Nov. 2017].

[16] Maitah, M., Procházka, P., Čermák, M. and Šrédl, K. (2016a) "Commodity Channel Index: Evaluation of Trading Rule of Agricultural Commodities", International Journal of Economics and Financial Issues, Vol. 6, No. 1, pp. 176-178. ISSN 2146-4138.

[17] Maitah, M., Procházka, P., Pachmann, A., Šrédl, K. and Řezbová, H. (2016b) "Economics of Palm Oil Empty Fruit Bunches Bio Briquettes in Indonesia", International Journal of Energy Economics and Policy, Vol. 6, No. 1, pp. 35-38. ISSN 2146-4553.

[18] Ministry of Agriculture of the Czech Republic (2004 -2007) "Green report of the Czech Republic", RIAI and Ministry of Agriculture, Prague. [Online]. Available: http://eagri.cz/public/web/mze/ ministerstvo-zemedelstvi/vyrocni-a-hodnotici-zpravy/zpravy-o-stavu-zemedelstvi/ [Accessed: 17 May 2018].

[19] Nešvera, V. (2006) "Prices in trade of the Czech Republic with member countries of the European Union", Politická ekonomie, Vol. 54, No. 2, pp. 214-226. ISSN 2336-8225.

[20] OECD (2007) "The OECD-FAO Agricultural Outlook 2007-2016". [Online]. Available: https:// www.oecd.org/tad/agricultural-trade/38893266.pdf [Accessed: 6 Nov. 2017].

[21] OECD (2011) "Globalisation, Comparative Advantage and the Changing Dynamics of Trade", OECD Publishing. [Online]. Available: http://www.oecd.org/publications/globalisation-comparativeadvantage-and-the-changing-dynamics-of-trade-9789264113084-en.htm [Accessed: 6 Nov. 2017].

[22] Pierce, J. R. and Schott, P. K. (2009) "A concordance between ten-digit U.S. Harmonized system codes and SIC/NAICS product classes and industries", Working Paper 15548, National Bureau of Economic Research. [Online]. Available: http://www.nber.org/papers/w15548 [Accessed: 6 Nov. 2017]. 
[23] Pohlová K. and Mezera J. (2014) "Analysis of Development of Czech Foreign Trade in Foods and Beverages", Agris on-line Papers in Economics and Informatics, Vol. 6, No. 4. p. 121-131. ISSN 1804-1930.

[24] Pohlová, K., Mezera, J. and Špička, J. (2016) "Czech foreign trade with meat and meat products", Acta Oeconomica Pragensia, Vol. 24, No. 2, pp. 63-80. ISSN 0572-3043. DOI 10.18267/j.aop.532.

[25] Pulkrábek, J., Peterová, J., Řezbová, H. and Urban, J. (2007) "Competitive ability and economy of bioethanol production crops", Listy cukrovarnické a řepařské, Vol. 123, No. 7-8, pp. 216-220. ISSN 1210-3306.

[26] Pohlová, K. (2017) "Agrarian Foreign Trade Yearbook 2016", Information study No. 114/2017, IAEI. Prague. ISBN 978-80-7271-226-7.

[27] Ratinger, T. and Matthews, A. (1999) "The competitiveness of the Czech agro-food sector in the context of EU Accession", FAO project TCP/CEH/8821.1999.

[28] Regmi, A., Gehlhar, M., Wainio, J., Vollrath, T., Johnston, P. and Kathuria, N. (2005) "Market Access for High-Value Foods", Agricultural Electronic Report, the Economic Research Service, USDA/ ERS Report No. 840, 2005.

[29] Rovný, P., Kováčiková, E. and Peprný, A. (2010) "Price development evaluation of chosen plant commodities in agrarian market in the Slovak Republic", Acta Universitatis Agriculturae et Silviculturae Mendelianae Brunensis, Vol. 58, No. 3, pp. 225-232. ISSN 1211-8516. DOI 10.11118/actaun201058030225.

[30] Řezbová, H., Maitah, M., and Sergienko, O. I. (2015) "EU Quota Sugar Market Concentration - the Main Drivers of EU Sugar Market", Agris on-Line Papers in Economics and Informatics, Vol. 7, No. 4, pp. 131-142. ISSN1804-1930.

[31] Šimáková, J. and Stavárek, D. (2015) "The effect of exchange rate on industry-level trade flows in Czechia", E \& M Ekonomie a management, Vol. 18, No. 4, pp. 150-165. ISSN 2336-5604. DOI 10.15240/tul/001/2015-4-011.

[32] Vokorokosova, R. (2005) "To some methods for measuring competitiveness of Slovak and Czech foreign trade", Ekonomický časopis, Vol. 53, No. 8, pp- 808-823. ISSN 0013-3035.

[33] World Customs Organization (2017) "Harmonized System database", World Customs Organization. [Online]. Available: http://harmonizedsystem.wcoomdpublications.org/ [Accessed: 6 Nov. 2017].

\section{APPENDIX}

Old methodology - basic codes Regmi et al. (2005)

I. Bulk commodities

4-digit codes:

0902,0903,1001,1002,1003,1004,1005,1006,1007,1008,1201,1202,1204,1205,1206,1207,1801,2401

6-digit codes:

$090111,090112,140420$

II. Horticultural products

Calculated as the difference between total agricultural trade (HS $01-24$ ) minus the sum of other (three) categories. 
III. Semi-processed products

4-digit codes:

$0101,0102,0103,0104,0105,0106,0209,0301,0501,0502,0504,0505,0506,0507,0508,0510,0511,0713,1101,1$ $102,1103,1108,1109,1203,1208,1209,1211,1213,1214,1301,1302,1401,1404,1501,1502,1503,1505,1506,15$ $07,1508,1509,1510,1511,1512,1513,1514,1515,1516,1518,1520,1521,1522,1802,1803,1804,1805,2301,230$ $2,2303,2304,2305,2306,2308,2309$

6-digit codes:

$090190,170111,170112,170113,170114$

IV. Highly processed products

4-digit codes

$0201,0202,0203,0204,0205,0206,0207,0208,0210,0302,0303,0304,0305,0306,0307,0401,0402,0403,0404,0$ $405,0406,0407,0408,0409,0410,0710,0711,0712,0811,0812,0814,1104,1105,1106,1107,1504,1517,1601,16$ $02,1603,1604,1605,1702,1703,1704,1806,1901,1902,1903,1904,1905,2001,2002,2003,2004,2005,2006,200$ $7,2008,2009,2101,2102,2103,2104,2105,2106,2201,2202,2203,2204,2205,2206,2207,2208,2209,2402,2403$

6-digit codes:

$090121,090122,121220,170191,170199,121221,121229$

Newly proposed methodology - Pohlova et al. (2017)

I. Unprocessed commodities

01,0301,03062210,03063210,030710,030711,030721,030731,030741,030742,030751,03076090,03076000, 030771,030781,030782,030791,030811,030821,03083010,03089010,04012099,0407,0409,0410,0501,0503 $, 0508,05090010,05119931,06,0701,0702,0703,0704,0705,0706,0707,0708,0709,0713,07141000,07141091$ $, 07141098,07141099,07142010,07143000,07144000,07145000,07149011,07149019,07149020,07149090,0$ $80119,080121,080131,080211,080221,080231,080241,080251,080261,080240,080250,08030011,0803001$ $9,08031010,08039010,080410,08042010,080430,080440,080450,0805,080610,0807,0808,0809,0810,0901$ $11,090220,090240,0903,090411,09042010,09042030,09042110,09042190,090500,090510,090610,090611$, 090619,090700,090710,09081000,09082000,09081010,09082010,090811,090821,090831,090921,090931, 090961,09091000,09092000,09093000,09094000,09095000,09093011,09093019,09094011,09094019,090 $95011,09095019,091010,091011,09102010,09109110,09109931,09109933,09109991,09109910,09109950$, $09104011,09104013,09104090,1001,1002,1003,1004,1005,100610,1007,1008,1201,120210,120230,12024$ $1,1204,1205,12060010,12060099,1207,1209,121010,1211,12129180,12121010,121292,121293,121294,12$ $121091,12129941,12129095,12129910,12129920,12129930,12129970,12129980,12129990,1213,1214901$ $0,1301,1401,1402,1403,1404,15211010,15219091,220190,2401$

II. Less processed products

Calculated as the difference between total agricultural trade (the sum of HS $01-24$ ) minus the sum of other two categories (Unprocessed commodities and highly processed commodities).

III. Highly processed products

021011,021012,021019,021020,021091,021092,021093,02109010,02109011,02109019,02109021,0210902 $9,02109031,02109039,02109041,02109049,02109060,02109071,02109079,02109080,02109910,02109921$ ,02109929,02109931,02109939,02109941,02109949,02109951,02109959,02109960,02109971,02109979,0 2109980,02109985,030520,030530,030531,030532,030539,030541,030542,030543,030544,030549,03055 $1,030553,030554,030559,030561,030561,030562,030563,030564,030569,030571,030572,030579,0402109$ $1,04021099,040229,040299,0403,04041002,04041004,04041006,04041012,04041014,04041016,04041026$ ,04041028,04041032,0404034,04041036,04041038,04041072,04041074,04041076,04041078,04041082,04 $041084,040490,040520,0406,1517,16,170191,170199,1702,1704,1806,1901,1902,1904,1905,20,21,2202,2$ 203,2204,2205,2206,2207,2208,2209,2309,2402,240311,240399 